\title{
Os longos anos 1960 como um golpe por direitos no vitorianismo ocidental
}

The long 1960s' as struggle for rights in the victorian western hemisphere

\section{Raphael Barreiros de Farias}

raphaelbfarias.rbdf@gmail.com

Mestrando em História social da Cultura na PUC-Rio.

\section{Resumo}

O objetivo desse artigo é observar como as mudanças comportamentais dos longos anos 1960 representaram uma busca pela ampliação de direitos com relação aos então modelos vitorianos idealizados de comportamento, moralidade e gênero no hemisfério ocidental. Serão tidos como exemplo de descontinuidade de valores vitorianos as experiências de três países no período: Estados Unidos, França e Inglaterra.

Palavras-chave: época vitoriana; moralidade; pós-guerra; mudanças comportamentais.

\begin{abstract}
The aim of this article is to observe how the changing behaviors in the long 1960s' represented a search for more rights in a victorian postwar Western Hemisphere that idealized models of behavior, morality, and gender. It will be taken as examples of victorian values discontinuities three countries' experiences during that period: USA, France and England.
\end{abstract}

Keywords: victorian age; morality; postwar, changing behaviors. 


\section{Introdução}

Para dar conta da tarefa proposta nesse artigo - perceber o golpe que os anos 1960 representaram para os valores vitorianos amplamente presentes na época do pós-Guerra - se usará como fonte certa bibliografia referente aos três países propostos para análise - Estados Unidos, França e Inglaterra - no recorte histórico situado entre as décadas de 1940 e 1970, dando conta da época logo anterior e dos longos anos 1960 propriamente ditos. Ter-se-á como objetivo analisar brevemente essa bibliografia no intuito de observar o que ela revela sobre a descontinuidade comportamental e de refletir a respeito de algumas questões sobre esse processo de liberalização dos costumes e ampliação de direitos.

Para cumprir o objetivo que o artigo propõe, é necessário antes refletir um pouco sobre o processo histórico desde a Revolução Industrial em prol de melhor entrar na questão central do texto. Portanto, segue uma breve discussão a seguir sobre essa revolução e, a posteriori, sua relação com a Era Vitoriana, em que ela consiste e seus valores.

\section{A Revolução Industrial}

A Revolução Industrial, iniciada na Inglaterra entre os séculos XVII e XVIII, causou profundas mudanças nas relações e estruturas sociais. O processo de industrialização levou ao crescimento de cidades e à explosão demográfica nos espaços urbanos. O valor de produção das terras na Inglaterra e os consequentes cercamentos delas levaram ao êxodo rural da população camponesa inglesa. Essa massa de indivíduos desalojados do campo passou a ocupar as urbes industriais, onde foram viver normalmente sob condições precárias em cortiços e favelas, locais superlotados e sem nenhum saneamento. Em conjunto à rotina desgastante dos trabalhos em fábricas e serviços, e mesmo outros fatores, isso resultou em surtos de doenças de todas as naturezas.

As cidades e as áreas industriais cresciam rapidamente, sem planejamento ou supervisão, e os serviços mais elementares da vida da cidade fracassavam na tentativa de manter o mesmo passo: a limpeza das ruas, o fornecimento de água, os serviços sanitários, para não mencionarmos as condições habitacionais da classe trabalhadora. A consequência mais patente desta deterioração urbana foi o reaparecimento das grandes epidemias de doenças contagiosas (...), notadamente a cólera, que reconquistou a Europa a partir de 1831 (...). (HOBSBAWM, 1977, p.224) 
FARIAS, Raphael Barreiros. Os longos anos 1960 como um golpe por direitos no vitorianismo ocidental. Dignidade Re-Vista, v.6 n.10, jul 2020.

Apesar do crescimento e da importância das grandes cidades no período, a maior parte da população global seguia vivendo em espaços rurais (HOHENBERG e LEES, 1995), e muitos valores e costumes associados a este universo continuavam a guiar a vida da quase unanimidade das classes populares e da maioria das classes mais abastadas - mesmo que vivessem em espaços urbanos. Isso se dava principalmente devido à procedência da esmagadora maioria da população, que estava de alguma forma vinculada diretamente ao campo. O encontro nos territórios urbanos dessa grande massa de pessoas, em grande parte componentes das classes populares empobrecidas, provenientes de regiões agrárias - onde prevaleciam ideais de comportamento ditos tradicionais, que tinham como foco principal a reprodução social no meio rural -, levou a algumas mudanças na esfera comportamental. Quando essas pessoas de origem camponesa, acostumadas ao convívio apenas com familiares e pessoas próximas a este núcleo, se veem habitando conglomerados urbanos, há um incremento nas possibilidades concernentes aos comportamentos sexuais e de gênero. Explicando de outra forma, o leque de possibilidades sexuais e comportamentais de parte da população se amplia à época da Revolução Industrial devido ao convívio de grandes massas populacionais nos espaços urbanos aglomerados (GRIFFIN, 2013).

\section{A Era Vitoriana e vitorianismo}

A época vitoriana do contexto de pós-Revolução Industrial é presente no imaginário popular como um período de repressão sexual, moralidade restritiva e papéis de gênero fortemente demarcados. Apesar de estudos históricos mais recentes apontarem as contradições dessa afirmação - como por exemplo que as classes populares tinham, por diversas razões, mais dificuldade em seguir o modelo comportamental idealizado no período, realizando uma série de negociações ${ }^{1}$ - ela não consiste uma inverdade. Modelos ideais de papéis de gênero domesticidade feminina e trabalho masculino provedor -, respeitabilidade e moralidade eram bastante enfatizados e cobrados.

Nesse momento, as camadas médias das sociedades ocidentais surgiram com força no cenário político, social e econômico. Foi uma época marcada pelo surgimento do que podemos chamar de cultura de classe média - em consequência da ampliação e ascensão ao protagonismo

\footnotetext{
${ }^{1}$ A ideia expressa nessa frase é corroborada pelos trabalhos de Heleieth Saffioti (2013) e Chitra Joshi (2009). Segundo a última, principalmente classes populares racializadas passavam por dificuldades para atender esses padrões vitorianos idealizados.

DIGNIDADE RE-VISTA | ISSN2525-698X| 2020 | V. V | N. 10 | Um olhar para a Amazônia: riquezas e diversidades | Sessão livre. Pastoral Universitária Anchieta PUC-RIO.
} 
social das camadas médias - e os valores e ideais típicos da Era Vitoriana são comumente relacionados a essa parcela da sociedade. A Era Vitoriana foi marcada, ainda, pelo ideal de amor-romântico nas relações íntimo-eróticas, que consistia nas relações erótico-sexuais entre casais monogâmicos heterossexuais que completassem eternamente todas as necessidades sentimentais um do outro, cada um desenvolvendo um papel específico no relacionamento, condizente com a idealização comportamental esperada de seu gênero biológico (GIDDENS, 1992).

O conceito de vitorianismo usado neste artigo segue a definição empregada por Peter Gay (2002), e refere-se à cultura e à mentalidade típicas da época burguesa de consolidação do capitalismo durante a Revolução Industrial, e o imediato período posterior - em que o racionalismo fruto das luzes iluministas havia se consagrado na esfera intelectual. No caso, esse conceito não está atrelado apenas à Inglaterra e ao período do reinado da Rainha Vitória necessariamente, mas sim a todo o mundo ocidental - por mais complexa e construída que seja a ideia de ocidente - ao longo do recorte temporal que vai de finais do século XVIII a meados do século XX.

Customary usage has long defined "Victorian" as pointing to British, a even more narrowly, to English tastes, morals and manners. Its meaning has never been confined to the reign of Queen Victoria, since it is generally victorians before her accession in 1837 and after her death in 1901. [...] there were also Victorians outside her realm. [...] and I believe that it can be properly generalized even further. (GAY, 2002)

É importante ressaltar que, apesar da prevalência da ordem comportamental vitoriana ao longo de dois séculos, os ideais vitorianos foram negociados em alguns momentos devido a necessidades histórico-sociais objetivas - como, por exemplo, o momento das grandes guerras, quando o ideal de domesticidade feminina foi deixado de lado porque as mulheres eram necessárias como mão-de-obra nas fábricas e trabalhando na terra, enquanto os homens lutavam nos campos de batalha. Como já mencionado, havia também pessoas que por diversos motivos, principalmente por razões de pertencimento a uma determinada classe, raça e/ou etnia, não conseguiam atender aos padrões vitorianos idealizados - esses indivíduos negociaram e se apropriaram desses valores e padrões das mais variadas maneiras possíveis. Além disso, ao longo de toda a Era Vitoriana houve contestações ao modelo comportamental, sexual e moral estabelecido - principalmente durante a primeira metade do século $\mathrm{XX}$-, em grande parte pela impossibilidade e reticência de alguns indivíduos e grupos sociais em aderirem aos valores 
vitorianos. ${ }^{2}$ Segundo Peter N. Stearns (2017) e Jeffrey Weeks (2018), a repressão e rígida moralidade características da época que aqui denominamos vitoriana foram uma resposta dada pela sociedade ocidental - naquela época ainda extremamente adepta aos valores judaicocristãos tradicionais, presentes principalmente nos meios rurais - às novas possibilidades comportamentais geradas pelos conglomerados urbanos e pelo enriquecimento de certos setores sociais devido à Revolução Industrial.

Herbert Marcuse (1991) traz outro viés à discussão, ao afirmar que o capitalismo inicial do pós-Revolução Industrial necessitava dos rígidos controles sexuais e comportamentais do vitorianismo para consolidar o modo de produção capitalista através de mecanismos de reprodução social - processo este de manutenção das condições sociais e de vida das diferentes classes, principalmente das mais empobrecidas, o qual deveria ser intenso e eficaz, porém, ao mesmo tempo, de alguma maneira regulado. Segundo o autor, a partir da segunda metade do século XX, com o capitalismo já em fase tardia, se consolida o processo que ele chama de repressive desublimation, que consiste na aceitação e legalização, por parte do sistema capitalista, pelo menos em países centrais do capitalismo, de elementos vistos pelas sociedades e considerados pelas próprias instituições mais representantes do modo de produção capitalista como inadmissíveis anteriormente.

Apesar das noções de respeitabilidade e moralidade terem sido amplamente reforçadas durante a época vitoriana, os modelos comportamentais prezados pelo vitorianismo não foram criados nesse período. Em praticamente todas as sociedades tradicionais - em parte devido às suas fortes bases rurais - havia bastante rigidez ao tratar-se de valores que concerniam à moral, ao comportamento e à sexualidade. A explicação mais convincente sobre o motivo desse fenômeno é que em sociedades tradicionais, majoritariamente agrárias, o controle dos corpos principalmente dos corpos femininos - se fazia essencial para que posteriormente não houvesse dúvidas com relação à origem da descendência em prol de heranças e posse de terras por parte de descendentes consanguíneos dos proprietários originais. Também, ainda, para que não houvesse explosões demográficas ou grandes surtos de doenças venéreas.

\section{A dialética de Chomsky, o período pós-guerra e os longos anos 1960}

\footnotetext{
${ }^{2}$ Um dos maiores exemplos de contestação aos valores vitorianos durante a primeira metade do século XX foi o clima do pós-Primeira Guerra Mundial, caracterizado pelos chamados loucos anos 1920; e os escritos e militância, principalmente de socialistas e anarquistas, como por exemplo Havelock Ellis, Emma Goldman, Alexandra Kollontai, entre outros.
} 
FARIAS, Raphael Barreiros. Os longos anos 1960 como um golpe por direitos no vitorianismo ocidental. Dignidade Re-Vista, v.6 n.10, jul 2020.

Noam Chomsky (2017) argumenta que a história da sociedade norte-americana é permeada pela dialética entre forças aristocráticas e forças democratizantes - ideia atribuída por ele a Thomas Jefferson. As forças aristocráticas consistiriam nos movimentos e ações que visassem limitar a conquista de direitos e a inclusão de pessoas no processo democrático de cidadania, enquanto as forças democratizantes consistiriam nos movimentos e ações que visassem ampliar a aquisição de direitos ao maior número possível de pessoas e a inclusão do máximo de indivíduos no processo democrático de cidadania. Segundo o próprio autor, os longos anos 1960 foram uma época na qual prevaleceram tendências democratizantes.

Seguindo esse pensamento, apresentamos o etos do pós-guerra em contraposição ao etos dos longos anos 1960. O primeiro, como representante das forças aristocráticas simbolizadas pelo vitorianismo que sobreviveu até então, e o último, como um movimento representante das forças democratizantes que surgiu em oposição ao anterior. Esses dois etos serão considerados como elementos componentes de um processo histórico de liberalização dos costumes e ampliação de direitos que teve seu auge entre as décadas de 1950 e 1970, sendo precedido por um momento anterior conservador e tradicionalista $r$ no imediato pós-Segunda Grande Guerra.

Sobre o período pós-guerra na Europa, esse consistiu na época que a sociedade europeia tentava se reconstruir da destruição que a Segunda Guerra havia provocado. Segundo Tony Judt, esse período foi de restauração e manutenção da ordem vitoriana no velho continente - e também nos Estados Unidos e em todo o hemisfério ocidental.

(...) description of industrial Wallonia in the 1950s, (...) could as well be applied to most of western Europe in these years. (...) In many of its essential features, daily life in the first decade after World War Two would have been thoroughly familiar to men and women of fifty years earlier. (...) The same sense of suspended time hung over much of continental Europe too. (JUDT, 2005, p.226-27)

Essa ideia de período pós-guerra pode ser adaptada também à realidade norte-americana, apesar do autor se propor a pensar exclusivamente o contexto europeu. Os EUA não estavam destruídos como a Europa e viviam um bom momento econômico no período pós-guerra, mas com o fim do conflito os modelos sexuais e comportamentais vitorianos eram constantemente reafirmados na sociedade estadunidense, também.

O conceito de longos anos 1960 consiste na ideia que este período simboliza o etos de contestação, rebeldia e protagonismo da juventude, que não se restringe rigidamente aos anos que compõem essa década do século $\mathrm{XX}$, mas se amplia - tanto aos anos que a precederam 
como aos que a procederam imediatamente. Portanto, consideramos, neste texto, o período que se estende da segunda metade da década de 1950 à primeira parcela da década de 1970.

\begin{abstract}
Os anos 1960 americanos não foram uniformemente rebeldes, mais que os anos 1950 foram uniformemente conservadores ou os anos 1970 uniformemente quiescentes. Mesmo se as décadas, como os séculos, pudessem ser consideradas como começando com algum atraso, de modo que pudéssemos datar os anos 1960 "reais" de, digamos, 1964 a 1974, nem assim os contrastes convencionais funcionariam perfeitamente. (...) Assim, "os anos 1960" é menos uma expressão para o estado da nação do que uma expressão guia para um estado mental - radical, voltado para a juventude, contracultural, de fácil condução, comprometido com as atitudes da nova esquerda, direitos da minoria, consciência negra, drogas, experiência psicodélica, protesto e dissensão. (BRADBURY et al., 1981, p.335)
\end{abstract}

É importante notar que, originalmente, o conceito de longos anos 1960 é pensado tendo como base o contexto estadunidense, mas aqui utilizado também refletindo os contextos inglês e francês. Isso é possível graças a elementos presentes no conceito serem também compatíveis à realidade dos citados países europeus. O principal desses elementos é o gap geracional - a ideia que a sociedade norte-americana dos longos anos 1960 era protagonizada principalmente por jovens e idosos devido às muitas vidas ceifadas pela Segunda Grande Guerra e ao boom demográfico durante e logo posterior à ela. Esse fator do gap geracional era ainda mais presente na França e na Inglaterra, pois nesses países o número de óbitos resultantes do conflito era superior ao dos Estados Unidos.

\title{
Estados Unidos
}

Os EUA viveram um grande crescimento econômico ao longo e principalmente após o término da Segunda Grande Guerra. Como já foi mencionado anteriormente, durante o conflito houve crescimento da mão-de-obra feminina em fábricas e serviços, porque essas trabalhadoras foram necessárias devido à falta de trabalhadores homens, que haviam sido mobilizados, em parte, pelas forças armadas para travar a guerra nos oceanos e na Europa. Como resultado disso, durante a guerra as mulheres assumiram um pouco mais de protagonismo social e econômico. Ou seja, durante a guerra houve uma negociação dos valores vitorianos com relação ao ideal feminino de domesticidade por causa das necessidades socioeconômicas práticas do mundo sob os transtornos do conflito. Além disso, com muitos homens fora do país, algumas mulheres assumiram a chefia prática de seus domicílios, havendo também uma certa ruptura do ideal vitoriano de autoridade máxima masculina sobre a casa e os filhos. 
FARIAS, Raphael Barreiros. Os longos anos 1960 como um golpe por direitos no vitorianismo ocidental. Dignidade Re-Vista, v.6 n.10, jul 2020.

No período pós-guerra, toma forma uma reafirmação dos valores vitorianos em oposição à anterior negociação deles, em função das necessidades objetivas da guerra. As mulheres que haviam feito parte da mão-de-obra durante o conflito foram se retirando dos espaços de trabalho. Isso se deu por vontade própria de muitas, que ao fim da guerra decidiram se casar e constituir família, ou mesmo por demissões em massa de mulheres, pois os empregadores, havendo novamente homens disponíveis para assumir os cargos que haviam sido ocupados por mulheres ao longo do conflito, preferiam dar os empregos às pessoas do sexo masculino. "After the war many women who had joined the work force returned to being housewives. Managing a home in the suburbs and raising a family became the goal of most women during the 1950s" (MINTZ, 1988, p.177). O ideal vitoriano de domesticidade feminina e trabalho masculino provedor foi constantemente reafirmado por representantes do Estado, em políticas públicas e pela mídia ${ }^{3}$. Cuidar da casa e dos filhos era tido como objetivo de vida das mulheres. Elas deveriam ser o suporte da família e garantir a estabilidade emocional da prole e do marido, garantindo que ele fosse trabalhar fora para conseguir a renda familiar sem preocupações com as atividades domésticas e a criação dos filhos; e garantir a renda da família era tido como objetivo central de vida dos homens. Dessa maneira, quem não cumpria esses papéis de gênero era visto como desajustado. As mulheres, como as loucas ou coitadas que não haviam conseguido se casar, ou que não o queriam, e os homens, como imaturos ou irresponsáveis que não se comprometiam com uma família. Havia constante temor por parte dos pais que seus filhos se tornassem desajustados, ou seja, não cumprissem esses ideais de gênero ${ }^{4}$. Para evitar que isso acontecesse, os pais deveriam tentar ao máximo seguir os ideais e valores vitorianos à risca, passando esses valores à sua descendência.

O etos dos longos 1960 se instaura nos EUA entre finais da década de 1950 e meados de 1970 em oposição ao etos do pós-guerra, contestando os ideais vitorianos, principalmente de gênero. Os diversos movimentos pelos direitos civis dos negros chamaram atenção para as famílias afro-americanas que, por questões de intercessão entre raça e classe, não conseguiam atender os ideais vitorianos de gênero e comportamento. Com inspiração da luta pelos direitos civis dos negros, mobilizou-se também pelos direitos das mulheres com o surgimento da segunda onda do movimento feminista, contestando-se papéis de gênero pré-concebidos.

\footnotetext{
${ }^{3} \mathrm{Na}$ mídia ao mesmo tempo que se reafirmavam papéis tradicionais de gênero durante o período pósguerra, principalmente em séries de TV como "Papai Sabe tudo" e "Eu Amo Lucy", se mostravam certos elementos de contestação nas indústrias do cinema, principalmente nos personagens interpretados por James Dean e Marlon Brando, e na música, em figuras como Elvis Presley, Chuck Barry e Little Richard. ${ }^{4}$ As demonstrações de contestação na indústria do entretenimento citadas acima contribuíam para o aumento desse temor por parte dos progenitores.
} 
As políticas públicas de assistência social e complementação de renda, à época fortemente baseadas no modelo ideal de salário familiar adquirido por um homem provedor, foram, a partir de então, amplamente contestadas. As últimas eram bastante problemáticas, pois o ideal vitoriano do homem provedor não atingia grande parte da sociedade norte-americana, principalmente sua parcela mais necessitada não branca, resultando na exclusão de boa parte da população estadunidense ao acesso a políticas governamentais, além dessas serem amplamente baseadas também em outras preconcepções de gênero. Muitas famílias que não atendiam o padrão familiar vitoriano de homem provedor e mulher dona de casa e cuidadora não conseguiam ter acesso aos benefícios dessas políticas públicas. Começou-se, então, a propor o planejamento de políticas públicas não tendo tanto em mente a proteção contra o desemprego formal - já que grande parte das classes populares não brancas não tinha acesso a empregos formais -, como era de praxe até então. Propôs-se passar a pensar o planejamento de políticas públicas de forma a combater a pobreza de maneira mais ampliada, e não tendo como modelo familiar único a família nuclear vitoriana idealizada - composta por pai provedor, mãe dona de casa e filhos -, de maneira a ampliar a assistência social governamental a outros indivíduos e modelos familiares, na tentativa de atender a todos os cidadãos necessitados de auxílio do Estado (SELF, 2012).

O etos dos longos anos 1960 pode ser percebido nos Estados Unidos, também, principalmente por alguns casos de embates judiciais que chegaram à Suprema Corte Norteamericana. Os mais emblemáticos sendo Griswold v. Connecticut (1965), que resultou na legalização nacional dos contraceptivos, e Roe v. Wade (1973), que resultou no reconhecimento do direito das mulheres ao aborto.

\section{França}

$\mathrm{Na}$ França, o vitorianismo se apresentava de maneira um pouco distinta dos outros países aqui analisados. A separação entre Estado e Igreja era mais bem definida na França que na Inglaterra e nos EUA - o que não significa que valores religiosos não permeassem o espaço público. Principalmente no concernente ao sistema educacional, esse é um país onde, desde a virada do século XIX para o XX, se preza a educação laica. Contestações à relação quase simbiótica entre Igreja Católica e Estado se apresentavam na França antes, desde as críticas feitas pelos autores iluministas franceses já no século XVIII - culminando no caráter secular da Revolução Francesa. O espírito de contestação à Igreja e o que essa instituição representava 
resultou num caráter secular fortemente presente na cultura francesa ao longo do século XX. Esse aspecto secular da sociedade francesa interferiu em algumas características do vitorianismo francês. Os valores e ideais vitorianos de comportamento e de gênero eram fortemente reforçados e justificados por questões morais e religiosas na maioria dos países ocidentais, mas a justificação dos ideais vitorianos, principalmente durante o século XX, se dava de forma mais científica e racional do que moral na França, devido ao forte secularismo típico da sociedade francesa.

Durante o período pós-guerra, os ideais vitorianos - fortemente reforçados com base em argumentação moral ao longo da Segunda Grande Guerra com o Governo de Vichy ${ }^{5}$ continuavam firmes na França, mesmo que fossem reafirmados de maneira mais racional, distintamente ao jeito mais moral como eram afirmados à época da ocupação alemã durante o conflito, “(...) ideas about breadwinner husbands as heads of the family and mothers/housewives as the heart had hardly disappeared" (FISHMAN, 2017, p.20). Como sugerido pela citação acima, o casamento era tido como caminho natural dos indivíduos principalmente das mulheres. Relações sexuais eram vistas como apropriadas apenas dentro dos limites do matrimônio monogâmico heterossexual. Mulheres e homens tinham papéis distintos e delimitados no âmbito familiar - era esperado dos homens que eles fossem os principais provedores da renda familiar e as mulheres fossem as principais cuidadoras das tarefas domésticas e dos filhos. Além disso, discussões sobre questões relacionadas à sexualidade eram extremamente restritas à certas esferas sociais - como, por exemplo, meios médico-científicos e alguns grupos vanguardistas e mais à esquerda do espectro político. A maioria da sociedade francesa se mantinha afastada dessas discussões e se guiava com base nos valores e ideais vitorianos de gênero e comportamento sexual pregados principalmente pela Igreja (DUCHEN, 1994).

Of the three generations alive in the 1960s, the oldest had been formed by the experience of the First World War. Most had direct links with the rural world. Their children, born in the 1920s and 1930s, and relatively few in number, had been marked by the experience of the Second World War and post-war austerity. [...] Their children, those of the 'baby boom', were far more numerous, and grew up in a world of plenty. These were the first children of the consumer society, their values profoundly different from those of either their parents or grandparents. (PRICE, 2014, p.328)

\footnotetext{
${ }^{5}$ Governo satélite na França da Alemanha Nazista, cujo líder foi Philippe Pétain. É normalmente chamado de Vichy devido ao nome da cidade na qual foi instalada a sede do Estado Francês durante o período.
} 
Como nos outros países analisados, os longos anos 1960, na França - por meio de seu etos, que permeou várias instituições - contestaram os valores e ideais vitorianos. Durante a década de 1950, as ideias contidas nas obras de Simone de Beauvoir - que questionam amplamente os papéis de gênero atribuídos às mulheres - eram constantemente apresentadas e discutidas em revistas femininas como Elle e Marie Claire, e levadas ao conhecimento do público, principalmente feminino. Em 1956, surge o movimento Maternité Hereuse - que adotou, quatro anos depois, o nome de Môvement Français pour le Planning Familial (MFPF) - que visava a divulgação e promoção do uso de contraceptivos. Entre 1967 e 1972, a contracepção é descriminalizada e legalizada na França. Em 1974, o governo da nação estipula a obrigatoriedade de educação sexual no currículo escolar nacional francês, consagrando a abertura ao debate sobre gênero e comportamento sexual no espaço público do país. Em 1975, é regulamentado legislativamente o direito das mulheres ao aborto na França.

Como disserta Anne-Claire Rebreyend (JACKSON et al, 2011), o etos dos longos anos 1960 foram sentidos principalmente nas relações familiares - âmbito no qual homens e mulheres franceses se permitiram sentir prazer sexual e buscar felicidade e satisfação pessoal em tipos de relacionamentos distintos dos modelos impostos pelos ideais de comportamento vitorianos, como, por exemplo, fora de casamentos legais.

\section{Inglaterra}

Como a França, a Inglaterra também sofreu bastante destruição e perdas humanas durante a Segunda Grande Guerra. Cidades ficaram destruídas por bombardeios, famílias inteiras viviam entre escombros de imóveis bombardeados - e continuaram a fazê-lo por um longo tempo no período pós-guerra. Bairros e habitações operárias tradicionais, em sua maioria, continuavam nos mesmos lugares que se situavam antes do conflito, apesar de muitas residências já estarem marcadas para demolição desde antes da guerra, devido a suas condições precárias. "In 1956 (...) though re-housing and slum clearanse programmes were well under way, many of the old working-class communities still existed virtually intact" (MARWICK, 2003, p.41). Durante os primeiros anos do pós-guerra, muito da rotina do período de batalhas se manteve presente no cotidiano inglês, como o racionamento de alguns produtos principalmente alimentos -, que perdurou até a primeira metade da década de 1950.

$\mathrm{Na}$ esfera sexual e comportamental, o período pós-guerra inglês foi também de babyboom e número crescente de casamentos. A expectativa sobre o cumprimento dos papéis 
idealizados de gênero, bastante característica dos valores vitorianos, se mantinha fortemente presente na esfera político-social inglesa. A função tida como essencial do caráter feminino era cuidar da casa e dos filhos. E dos homens era esperado que trabalhassem para cumprir a função de principais provedores da renda familiar. $O$ trecho abaixo ilustra bem essas expectativas de gênero. "The basic principle of a differentiation of roles as between husband and wife prevailed, with a wife's tasks clustering around her function as homemaker and child-rearer, just as a husband's clustered around his function as principal breadwinner" (MARWICK, 2003, p.43). Pesquisas feitas sobre a sociedade inglesa da época ${ }^{6}$ mostram que o que tornava uma esposa perfeita aos olhos da maioria das pessoas era ela ser atenciosa e cuidadosa com os membros do núcleo familiar, e o que fazia de um homem um marido ideal era ele não deixar jamais de prover a satisfação das necessidades econômicas da família. Enquanto isso, manter relações sexuais antes do casamento era desaprovado, principalmente com relação às mulheres, por mais da metade dos homens e por dois terços das mulheres inglesas - outro elemento típico do vitorianismo presente na sociedade inglesa do pós-guerra (SZRETER e FISHER, 2010).

Começa a perceber-se o etos dos longos anos 1960 na Inglaterra com o processo movido contra a editora Penguin Books sobre a publicação do livro de D. H. Lawrence Lady Chatterley's Lover - obra considerada imprópria na época pelas rígidas leis vitorianas, contra a obscenidade, que proibiam a publicação da obra por considerarem que representava um atentado à moralidade pública da sociedade inglesa. O julgamento desse processo - que concedeu vitória à editora quando reconheceu, em 1960, o seu direito de publicar o romance foi um golpe nos valores vitorianos ingleses e um dos primeiros sintomas da presença do etos dos longos anos 1960 naquele país. 1967 foi um ano no qual o etos dos longos 1960 se manifestou por excelência em terras inglesas. Nesse ano, o direito das mulheres ao aborto foi reconhecido. Ainda no mesmo ano, deixa-se de criminalizar a homossexualidade, dando-se fim, assim, à lei que era um dos maiores símbolos dos ideais vitorianos de gênero e comportamento na Inglaterra. Também, principalmente a partir de 1969, começa-se a ampliar e aperfeiçoar as leis sobre trâmites de divórcio - o que era bastante restrito até então, basicamente só pessoas das classes mais abastadas, e em maioria homens, conseguiam iniciar processos para divorciarse.

Como aponta o trabalho de Deborah Cohen (2013), na Inglaterra o etos dos longos anos 1960 pôde ser percebido principalmente pelo fim da superestimação da ideia de segredo e

\footnotetext{
${ }^{6}$ A mais importante dessas pesquisas tendo sido a realizada por Geoffrey Gorer em 1951. Outra pesquisa importante foi a realizada por Eustace Chesser em 1954.
} 
FARIAS, Raphael Barreiros. Os longos anos 1960 como um golpe por direitos no vitorianismo ocidental. Dignidade Re-Vista, v.6 n.10, jul 2020.

privacidade familiar, os quais considerava-se até então que deviam ser respeitado à risca, em prol de poder-se esconder as características consideradas vergonhosas das vidas privadas dos familiares ao mundo externo à família, podendo-se assim manter, pelo menos, as aparências de cumprimento dos ideais comportamentais vitorianos. Dessa forma, os ingleses começam a sentir-se mais livres na época para falar abertamente sobre questões relacionadas às suas vidas particulares que não atendiam às expectativas e aos valores vitorianos.

\section{Conclusão}

Como se pode perceber, tendo como base a bibliografia estudada, houve aperfeiçoamento e ampliação de algumas leis e reconhecimento de alguns direitos nos três países aqui analisados durante o período que classificamos como longos anos 1960, de maneira que mais indivíduos foram incorporados ao processo democrático de cidadania, adquirindo mais direitos garantidos. Pode-se afirmar que o etos contestatório dos longos anos 1960 foi sinônimo de ampliação dos direitos humanos com relação ao etos vitoriano do pós-guerra. 


\section{Referências bibliográficas}

BRADBURY, Malcolm; TEMPERLEY, Howard. (orgs.) Introdução aos Estudos Americanos. Rio de Janeiro: Editora Forense Universitária, 1981.

CHOMSKY, Noam. Requiem for the American Dream: the 10 principles of concentration of wealth \& power. Nova Iorque: Seven Stories Press, 2017.

COHEN, Deborah. Family Secrets, Living with Shame from the Victorians to the Present Day. Londres: Penguin Books, 2013.

DUCHEN, Claire. Women's Rights and Women's Lives in France 1944-68. Londres: Routledge, 1994.

FISHMAN, Sarah. From Vichy to the Sexual Revolution: Gender and Family Life in Postwar France. Nova Iorque: Oxford University Press, 2017.

GAY, Peter. Schnitzler's century: the making of middle-class culture 1815-1914. Nova Iorque: Norton \& Company, 2002.

GIDDENS, Anthony. A transformação da intimidade: sexualidade, amor \& erotismo nas sociedades modernas, São Paulo: UNESP, 1992.

GRIFFIN, Emma. Liberty's Down: a People's History of the Industrial Revolution. New Haven: Yale University Press, 2013.

HOBSBAWN, Eric. A Era das Revoluções. Rio de Janeiro: Paz e Terra, 1977.

HOHENBERG, Paul M.; LEES, Lynn H. The Making of Urban Europe (1000-1994). Cambrigde : Harvard Press, 1995.

JACKSON, Julian; MILNE, Anna-Louise; WILLIAMS, James S. (orgs.) May 68: Rethinking France's Last Revolution. Londres: Palgrave Macmillan, 2011.

JOSHI, Chitra. Além da polêmica do provedor: mulheres, trabalho e história do trabalho, Revista Mundos do trabalho, v.1, n.2, p.147-70, 2009.

JUDT, Tony. Postwar: a History of Europe Since 1945. Nova Iorque: Penguin Press, 2005.

MARCUSE, Herbert. One-Dimensional Man: studies in the ideology of advanced industrial society, 2.ed. Londres: Routledge, 2002.

MARWICK, Arthur. British Society Since 1945. 4.ed. Londres: Penguin Books, 2003.

MINTZ, Steven; KELLOGG, Susan. Domestic Revolutions: a Social History of American Family Life. Nova Iorque: Free Press, 1988.

PRICE, Roger. A Concise History of France. 3.ed. Cambridge: University Press, 2014. 
FARIAS, Raphael Barreiros. Os longos anos 1960 como um golpe por direitos no vitorianismo ocidental.

SAFFIOTI, Heleieth. A mulher na sociedade de classes. 2ed. São Paulo: Expressão Popular, 2013.

SELF, Robert O. All in the Family: the Realignment of American Democracy Since the 1960s. Nova Iorque: Hill and Wang, 2012.

STEARNS, Peter N. Sexuality in World's History. 2.ed. Nova Iorque: Routledge, 2017.

SZRETER, Simon; FISHER, Kate. Sex Before the Sexual Revolution: Intimate Life in England 1918-1963. Nova Iorque: Cambridge University Press, 2010.

WEEKS, Jeffrey. Sex, Politics and Society: The Regulation of Sexuality Since 1800. 4.ed. Nova Iorque: Routledge, 2018. 